\title{
Towards a Framework for Promoting Communication during Project Definition
}

\author{
Hafsa Chbaly ${ }^{1,2, *}$, Daniel Forgues ${ }^{1}$ and Samia Ben Rajeb ${ }^{2}$ \\ 1 Department of Construction Engineering, École de Technologie Supérieure, Montreal, QC H3C 1K3, Canada; \\ Daniel.Forgues@etsmtl.ca \\ 2 BATir Department, École Polytechnique de Bruxelles, Université Libre de Bruxelles (ULB), 1050 Brussels, Belgium; \\ Samia.Ben.Rajeb@ulb.ac.be \\ * Correspondence: Hafsa.chbaly.1@ens.etsmtl.ca
}

Citation: Chbaly, H.; Forgues, D.; Ben Rajeb, S. Towards a Framework for Promoting Communication during Project Definition. Sustainability 2021, 13, 9861. https:// doi.org/10.3390/su13179861

Academic Editor: Jorge de Brito

Received: 12 July 2021

Accepted: 23 August 2021

Published: 2 September 2021

Publisher's Note: MDPI stays neutral with regard to jurisdictional claims in published maps and institutional affiliations.

Copyright: (c) 2021 by the authors. Licensee MDPI, Basel, Switzerland. This article is an open access article distributed under the terms and conditions of the Creative Commons Attribution (CC BY) license (https:/ / creativecommons.org/licenses/by/ $4.0 /)$.

\begin{abstract}
Project definition refers to the first three stages of a project life cycle, namely planning, programming, and preliminary design during which client needs are identified and translated into design solutions. An ill-defined hospital project definition may lead to hospital-acquired infections or patient mortality. The traditional management practices have been proved to be inadequate since architects usually do not communicate with users, and thus do not have detailed knowledge about how services are performed in the building. There is the need for more knowledge about the subject to improve and thus promote client value generation. This study first reviews factors that impact the communication between architects and clients during project definition based on the literature. The study then offers a framework based on these factors to help managers assess and improve communication between professionals and clients. The validity of the framework will then be empirically validated and revised based on findings of a longitudinal mega-hospital case study. The main objective of the current investigation is to improve the project definition practices of complex projects, and the assumption is that an effective communication provides more value to end users, as well as better project performance in terms of environmental and social sustainability.
\end{abstract}

Keywords: project definition; alignment; communication; value

\section{Introduction}

The importance of effective definition and management of client needs during project definition (planning, programming, and preliminary design stages) for end user value generation have been emphasized by many researchers in the field [1-3]. A recent study by Safapour and Kermanshachi [4] highlighted that efficient project definition is the best way to minimize additional costs of project reworks. However, many findings demonstrate that the current conventional practices are "inadequate", especially in the context of complex projects $[2,5,6]$, leading to a lack of correspondence between what users need and the final product that they get, i.e., a building [2].

According to researchers such as Whelton, Ballard [7], Winch, Usmani [8], one of the main reasons for this problem is the poor communication between designers and clients. This issue is even more challenging since achieving effective communication is highly more complex and challenging in hospital projects $[9,10]$ because in such projects, there are multiple clients such as users (clinicians, patients, etc.), managers, and/or the government (paying client). Each type of client stakeholder has their own needs and interests that could sometimes be conflicting with those of others [11,12]. In the end, what usually happens is that only the "paying client" will be involved in the project definition process and "user" clients will usually be neglected $[13,14]$. The lack of involvement disrupts the potential for viewing and understanding all design angles (e.g., functional) and potentially leads to errors in the design. 
User-inclusive approaches such as Lean-led design have been suggested to address this issue $[15,16]$. Specific to hospitals, this structured approach has been recently proposed to be recruited throughout the process of project definition, starting from identifying client needs to proposing conceptual design solutions [16]. Unlike the traditional mindset, users in this approach play a significant role from the beginning of project definition since they are involved in the process of mapping, analyzing, and optimizing the care pathways (flows) that patients and clinicians would follow [17]. In this mindset, involving users in the process is seen as an essential step for a successful project [3] as it will help design professionals to communicate better with users to align their needs with the ultimate design solutions [14].

Lean-led design has gained popularity for improving quality of care in the United Kingdom and the United States $[5,11]$. However, empirical research about implementing this approach is still limited [18]. To the best of our knowledge, none of the studies have explored the impacts of such an inclusive approach on improving communication between clients and designers during the project definition stage. Furthermore, not enough information is available in the literature regarding a suitable model that could facilitate the communication between different parties during project definition of complex projects. As a result, there is the need for knowledge development in the form of empirical research studies about the dynamic processes of complex projects, client inclusion, and the overall impact of such a participative approach on the project definition process [18,19].

To address these gaps, we propose a framework that focuses on analyzing the factors that facilitate and/or hinder communication during the project definition stages. This framework has been developed based on a qualitative literature review and then evaluated during the three stages of project definition (planning, programming, and preliminary design) of a mega-hospital as our case study. The particularity of this mega-hospital is the use of Lean-led design to improve communication between users and design professionals.

The paper is organized as follows. Section 2 presents the methodology adopted to develop the aforementioned framework. Section 3 summarizes the different factors (enablers or inhibitors) impacting the communication during project definition, based on the literature and its evaluation and revision based on the case study. The Section 4 is a discussion and the last section is a conclusion, presenting the main contributions of this work and pointing to further avenues for future research.

\section{Methodology}

A qualitative research design was chosen to develop the conceptual framework of communication. Inspired by the case study method proposed by Yin [20], we followed three important steps: (1) qualitative literature review, (2) reviewing a longitudinal case study, and (3) comparison of literature review and case study results.

\subsection{Qualitative Literature Review}

Prior to performing the case study, a literature review was done to identify the facilitating and hindering factors that impact the communication between clients and design professionals during project definition to develop a communication framework. This framework represents a reference for the case study analysis, as recommended by Yin [20].

In order to choose papers and identify the existing factors in the literature that impact the communication, the systematic literature review methodology was used. Google scholar and Scopus databases were selected and searched with keywords such as (("communication" OR "enable *" OR "hinder *") AND ("project definition") AND ("construction industry" OR "hospital" OR “Lean-led Design" OR “Lean" OR "construction project management")) AND ("hospital" OR "complex project"). Three criteria were then used for further screening:

1. All the keywords must have been in either the abstract, the introduction or list of the keywords of the study; to ensure the selection of directly related papers. 
2. Survey data or statistical reports of results were excluded since the chosen research strategy was qualitative.

3. All papers written in languages other than English, French, or Spanish were excluded. After final screening, 60 papers remained from which we identified the factors.

\subsection{Longitudinal Case Study}

After identifying the communication factors based on the literature and developing a conceptual framework, the objective of step 2 was to identify communication factors based on a longitudinal case study.

\subsubsection{Rational of a Single Case Study}

The chosen case study is a $208,185 \mathrm{~m}^{2}$ mega-hospital project in Canada. The rationale for the choice of this single case study was based on its "unique" context as well as the facility to access to data about the project definition stages, i.e., planning, programming, and preliminary design. This project is actually the largest hospital project in Canada and the first one implementing the Lean-led design approach during different stages of the project definition in Quebec. A Lean-led design approach was implemented by means of Kaizen (workshop) activities that marked the different stages of project definition. From May 2014 to November 2016, seven Kaizen activities were organized with the participation of the clinicians, patients, clinical managers, project managers, and design professionals, with the aim of Kaizen improving communication and understanding between design professionals and users. According to Eisenhardt [21] and Yin [20], a "unique" case study should be appropriate for analyzing the dynamics within a particular phenomenon. It also represents a critical opportunity for testing a well-formulated theory.

\subsubsection{Data Collection and Analysis}

Data collection regarding the project focused on events of the last four years, during the project definition stage. The combination of three methods of data collection was used: documentation, videos, and interviews.

Documentation: In this phase, almost 10,000 written project materials such as meeting reports and PowerPoint presentations of Lean workshops were reviewed. According to Myers [22], documentation review is a key step in any data collection strategy and usually provides more comprehensive information about the phenomenon in question.

Videos: Six 4 to 5 min videos recorded by the hospital staff were analyzed. These videos described the objectives, achievements, and participant testimonies regarding Leanled design activities

Interviews: 28 semi-structured interviews were organized between 2019 and 2020 with different stakeholders (users, design professionals, managers, etc.) that had participated in the process of project definition of the new hospital (Table 1). As showing in the table only six users were interviewed. The rational for that is the fact that the Lean-led design approach was implemented in the mega hospital between 2014 and 2016, while our data collection was between 2019 and 2020. During this period, it was challenging to interview the clinicians and patients that have participated during the different kaizen. For instance, between 2016 and 2020, three patients have died, and seven clinicians have cancelled our meeting due to the COVID situation. However, even though the number of the interviewees seems to be not statistically relevant, the profiles chosen are representative to all participant of the project definition. In fact, during the interviews different profiles were involved such as the kaizen organizers, the professionals (design and construction) and the clients (project managers and users). In the client's profile, the clinicians and the patients were representative of the main three important hospital areas, ambulatory, hospital, and critical, that involve many interconnected hospital services. Let us take an example of critical care clinicians. These clinicians receive patients in an emergency situation and should collaborate with clinicians in other services such as (radiology, surgery, resuscitation, etc.) in order to save patients. This makes them aware of the diverse existent flows (e.g., patient, 
information, etc.) and links between these services. Furthermore, all the respondents have participated in at least four kaizen, which means that they have a general view of the project definition process of the new mega hospital.

Table 1. Overview of respondents.

\begin{tabular}{ccc}
\hline Respondents & \multicolumn{2}{c}{ Nb of Interviewees } \\
\cline { 2 - 3 } & $\mathbf{2 0 1 9}$ & $\mathbf{2 0 2 0}$ \\
\hline Members of the clinical management & 2 & 3 \\
\hline Lean agent & 1 & 1 \\
\hline Mechanical, electrical, plumbing engineer & 2 & 1 \\
\hline Structural and civil engineer & 2 & 1 \\
\hline Design professionals mandated for programming stage & 3 & 1 \\
\hline Design professionals mandated for design stage & 1 & 1 \\
\hline Project manager & 1 & 2 \\
\hline Clinicians & 3 \\
\hline Patients & 3 \\
\hline
\end{tabular}

The study was conducted in accordance with the Declaration of Helsinki, and the protocol was approved by the Ethics Committee of École de technologie supérieure (reference number H20181105). All interviewees received, before they participated in the study, an email explaining what the research project was, with a consent for inclusion to sign. Following the proposed appointment, an email was sent to confirm the time and place of the appointment. Then, a final reminder email was sent the day before the meeting. The duration of the interviews was somewhere between 30 and $120 \mathrm{~min}$, varying depending on how much information an interviewee had or was willing to share.

The interview data were recorded, transcribed, and coded with a qualitative data analysis tool, namely NVivo, to firstly develop a comprehensive view of the organizational phenomenon and secondly, unveil the main facilitating and inhibiting factors that can potentially impact communication among the involved parties in the project. A hybrid analysis strategy, similar to what has been used by others such as Malina and Selto [23], was recruited. This approach and permits empirical flexibility (or theory revision). Thus, the coding contained elements of both theory building and testing.

We opted for three levels of coding. The first one being very disparate in which everything that was thought as relevant "verbatim" was coded. At this stage, we ended up with a lot of codes, but without a structure to link them. The second level involved a more selective coding approach. In this phase, the most important communication factors that repeated several times were identified. In the last level of coding, we created links and connections between the identified factors (second-level codes) in order to classify them into categories of facilitating or hindering.

The validity of the data collection and analysis was further strengthened by focusing on concrete events to understand the project definition process including different categories of participants (e.g., clients and professionals). Coordination and validation meetings within the research team ensured a common comprehension and a growing mutual understanding.

\subsection{Literature vs. Case Study Comparisons}

The objective of this step was to revise the framework developed during step 1, based on case study findings. The comparison between the literature and the case study allowed us to identify not only the potential similarities and divergences, but also novel relevant factors. 


\section{Findings}

This section is divided into two parts. The first part presents the findings of step 1: The conceptual framework developed based on the communication factors. The second section presents the findings of step 2 and 3: The identified factors based on the case study and evaluation of the framework.

\subsection{Conceptual Communication Framework}

Deriving from the Latin word "commūnicāre" meaning "to share," communication refers to the process of sharing a message through the exchange of knowledge, information, ideas, and feelings through speech, gesture, or writing [24]. This means that different factors impact the achievement of an effective communication Figure 1 summarizes the main facilitating and hindering communication factors that were identified based on our results, constituting a conceptual framework. Many hindering factors have been found to be the inverse of the facilitating ones (e.g., sharing of understanding and lack of understanding). However, not every facilitator's inverse is a hindering factor (e.g., co-locating the team members) and this is what justifies the categorization of factors into facilitating and influencing. Facilitating factors positively impact communication in a way that when addressed, they facilitate the communication and when not addressed do not hinder it (e.g., co-locating team members). Influencing factors, however, can both positively and negatively impact communication, meaning that when addressed, they facilitate and, when not addressed, hinder it (e.g., understanding). More details will be presented in the next section.

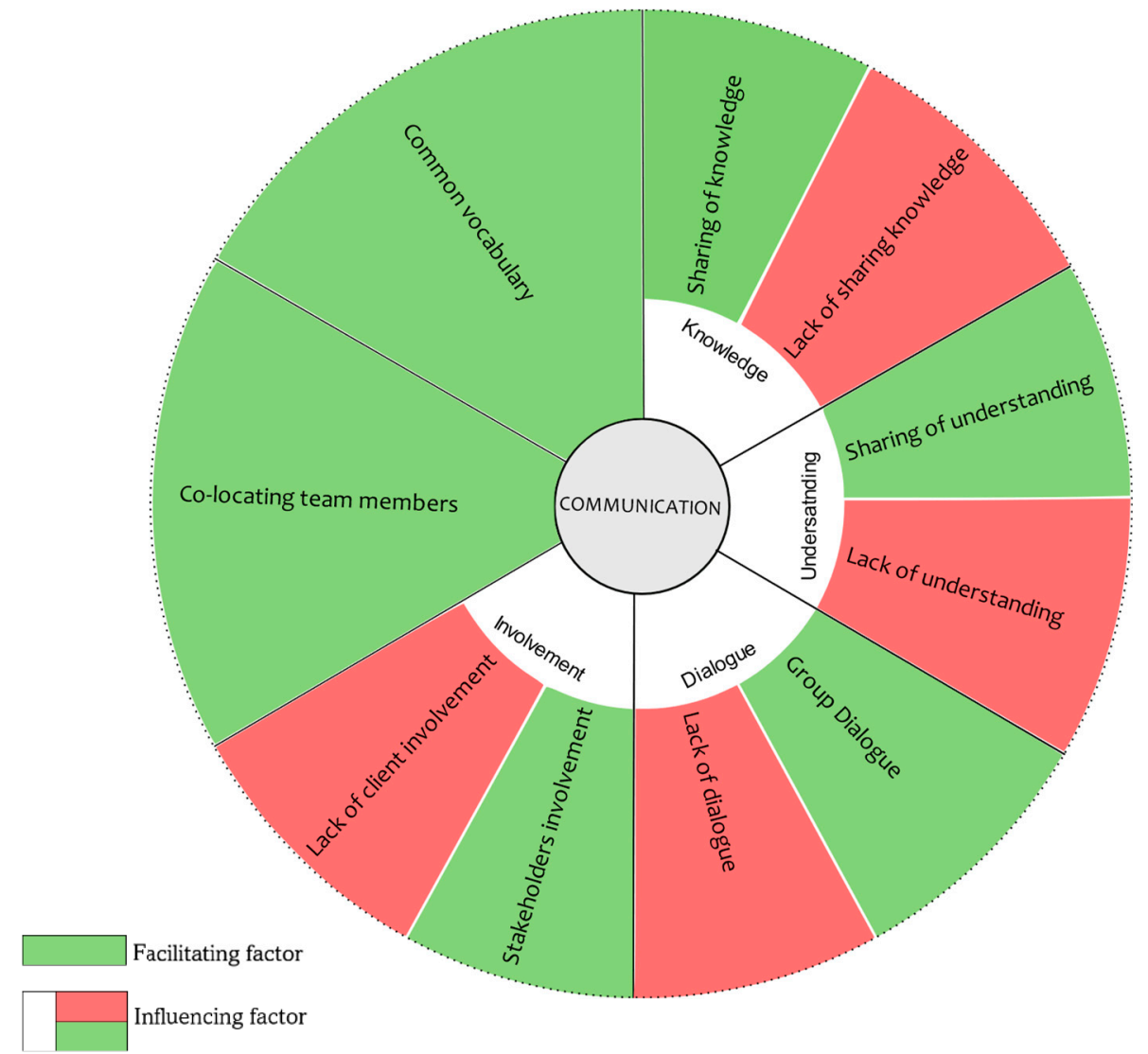

Figure 1. Conceptual framework: 2 facilitating factors, 4 hindering factors.

3.1.1. Influencing Factors

- Knowledge (sharing of knowledge/lack of knowledge sharing) 
Sharing of knowledge is the "push and pull found in the multiple, directional movement of data, information between individuals and groups for mutual benefit" [25]. According to the Construction Industry Institute [26], Griffith and Gibson [27], Bingham, Gibson [28], and Alm Lönnefjord and Johansson [29], knowledge sharing represents a pillar of communication. Without a shared knowledge, there is no effective communication. Actually, it is believed that communication only becomes fruitful when the sender shares knowledge (information) and the receiver understands the meaning of this information in the way the sender intended it. Whelton and Ballard [30] argue that sharing of knowledge continuously goes on during project definition. Design professionals interact with clients physically or remotely, however, using verbal communication (face-to-face or virtual meetings) to facilitate design decisions. According to Grunden and Hagood [16], implementation of Lean-led design should speed up sharing of knowledge between stakeholders by involving them in the process of project definition. Hicks and McGovern [11] point out that involving users in Lean activities make them more knowledgeable not only regarding the evolution of the project, but also regarding their own needs, thus consequently facilitating a sharing of understanding between stakeholders.

\section{- Understanding (sharing of understanding/lack of understanding)}

Sharing of understanding is defined as "similarity in individual perceptions of actors about a subject" [31] and is an indicator of effective communication. Authors adopting the Lean construction approach, such as Ballard [32], hold that open dialogue and sharing of knowledge facilitate mutual understanding. Forgues, Brunet and Chbaly [5] also hold the belief that Lean-led design, by means of a collaborative process, facilitates a mutual understanding between clients and professionals by considering the former's needs and the latter's design solutions. According to Kleinsmann and Valkenburg [31], lack of understanding causes unnecessary iterative loops as well as decreasing the quality of the final product because of the issues that have remained unresolved in the beginning.

- Dialogue (group dialogue/a lack of dialogue)

Group dialogue, identified as a communication enabler in construction projects, refers to a communication strategy used to understand the perspective of other people involved in a mutual activity $[33,34]$.

In the context of Lean construction, Whelton and Ballard [30] argue that the development of a dynamic group dialogue can facilitate sharing of knowledge among construction professionals and clients in the process of project definition and emphasize the importance of a project moderator to facilitate and manage the interactions between clients and design professionals.

While promoting group dialogue contributes to understanding the collective perspective of participants, lack of dialogue between client and designers leads to unclear and uncertain needs during the planning stage as well as unrealistic client expectations. A lack of dialogue generates other hindering factors including ill-defined needs [35] and requirements with unrealistic budgets and schedules [36].

- Involvement (Stakeholders (user) early involvement/Lack of client (user) involvement)

Stakeholder involvement is defined as the process of integrating people with different needs, goals, and cultures in a single cohesive and mutually supporting unit [37]. In the context of construction project management, Bingham and Gibson [28] believe that effective understanding and communication require early involvement of all stakeholders (owners, engineers, architects, and maintenance responsible). In the same research line and in the context of Lean construction, Johnson and Mazur [38], Whelton and Ballard [39] emphasize the importance of the concept of early involvement of users, namely the voice of the customer, to create a mutual understanding of needs, project problems, and potential solutions. Lack of user involvement during project definition leads to ineffective communication and a more effortful translation process [18]. 


\subsubsection{Facilitating Factors}

\section{- Common Vocabulary}

Vocabulary can be defined as a set of familiar words within a person's knowledge of a language. Researchers in the context of Lean construction emphasize the importance of developing a common vocabulary to facilitate the understanding and communication between construction professionals and clients [13,30,40]. Chocron and Schorlemmer [41] point out that development of a common vocabulary ensures efficient information interpretation and translation of needs on both sides of the project and add that when users and construction professionals use different vocabularies, the situation is comparable to "An English speaker trying to get a glass of wine in Italy" [41]. Developing a common vocabulary is in fact an important factor, especially in complex contexts such as hospitals where personnel from different backgrounds interact and contribute to the project with their own specific knowledge background [30].

- Co-locating Team Members

Sharing the same workspace with other team members is the core of the idea of colocating [25]. Co-locating team members has been recognized as a facilitating factor for communication. Heineman and Zeiss [42] argue that when team members are co-located, the face-to-face communication, and thus the alignment between them, is promoted. Van den Bulte and Moenaert [43] also hold the same belief and add that co-locating enhances the frequency of communication among team members. Other empirical studies have found that there is a positive correlation between co-locating people and their collaborative behavior; and finally, a higher level of shared understanding between actors [25,44,45].

Therefore, after identifying the conceptual framework based on the literature review, its validity will be evaluated in the context of the mega-hospital case study in the next sections.

\subsection{Factors Identified Based on the Case Study}

Figure 2 presents the different factors identified based on the case study. Actually, in addition to all the identified factors in the literature, new factors were identified in this case study. More precisely, six factors were similar to those identified in the literature ( 2 facilitating and 4 influencing) and five were newly identified: semantic ambiguity, loss of acquired knowledge, dividing group in silos, excessive involvement of clients, and dominating actors. One of these was classified as hindering (dominating actors) and four others as influencing factors since they represented the opposite of the others found in the literature. For example, semantic ambiguity (newly identified) is the opposite of common vocabulary, classified previously in the facilitating subcategory. For this reason, we decided to classify both of them in the influencing category, since one represents the opposite of the other, and they could be considered as one that positively influences communication when it is present and hinders it when it is not.

\subsubsection{Influencing Factors}

The table below (Table 2) summarizes communication influencing factors in each stage of the case study project definition. In this table, the new factors identified in the case study are in bold. The lines signify when the factor started and stopped being addressed in each stage. The green line refers to factors positively influencing communication, while the red signifies the factors negatively influencing communication. 


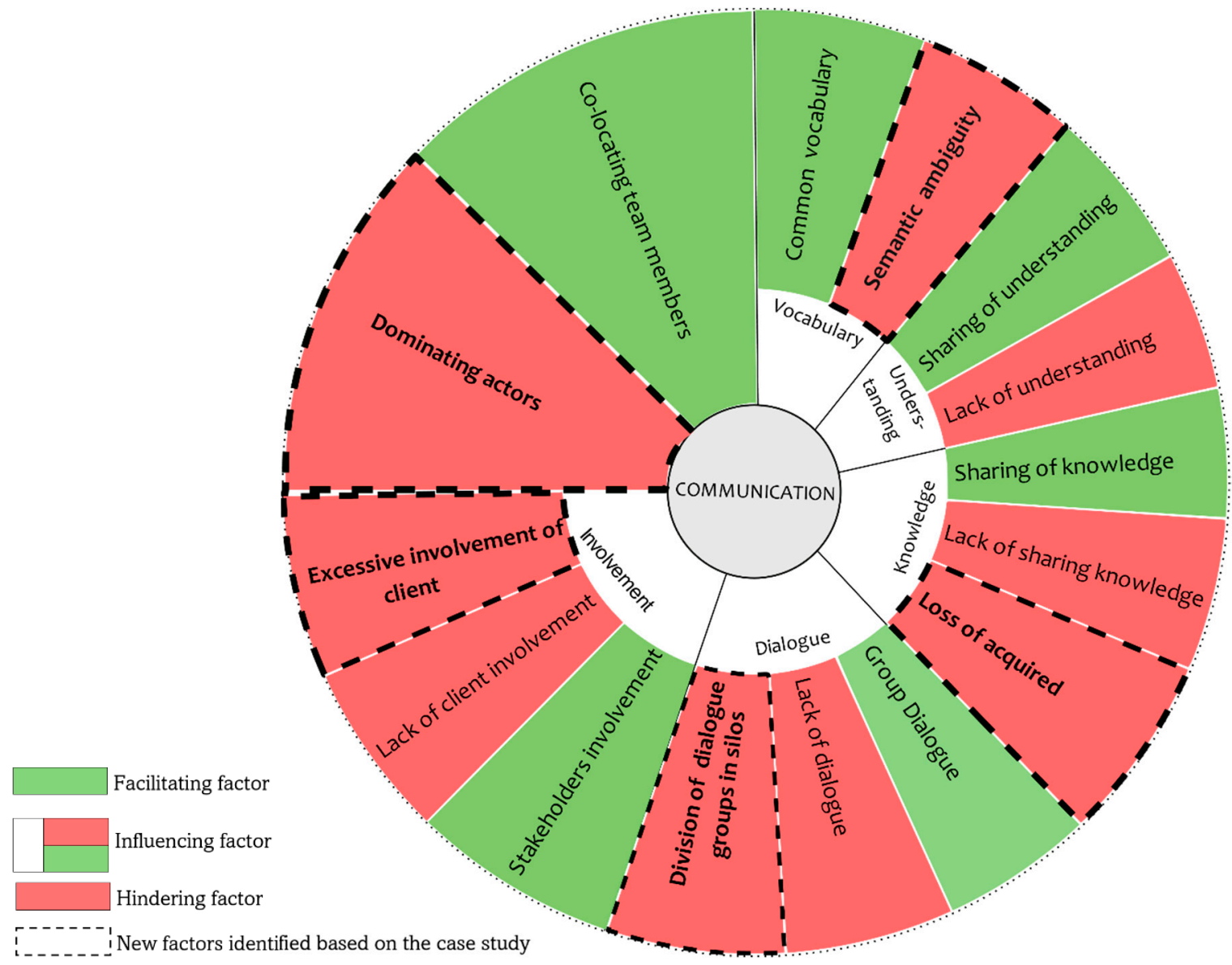

Figure 2. The revised conceptual framework based on findings of the case study: 1 facilitating, 1 hindering, and 5 influencing factors. Therefore, three categories of factors were identified: influencing, facilitating, and hindering.

Table 2. Influencing factors identified in the case study.

\begin{tabular}{|c|c|c|c|}
\hline Influencing Factors & Planning Stage & Programming Stage & Conceptual Design Stage \\
\hline \multirow{3}{*}{ Knowledge } & Sharing of knowledge & $\mathrm{c}$ & -0 \\
\hline & Lack of sharing knowledge & & 0 \\
\hline & Loss of acquired knowledge & & 0 \\
\hline \multirow{2}{*}{ Understanding } & Sharing of understanding & $\mathrm{c}$ & \multirow{2}{*}{0} \\
\hline & Lack of understanding & & \\
\hline \multirow{3}{*}{ Dialogue } & Group dialogue & $\mathrm{C}$ & $\mathrm{C}-\mathrm{-}$ \\
\hline & Lack of dialogue & & \\
\hline & Division of dialogue groups in silos & 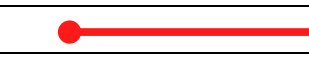 & 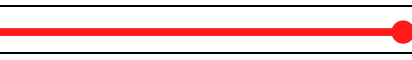 \\
\hline \multirow{3}{*}{ Involvement } & Stakeholders (user) early involvement & & $\longrightarrow$ \\
\hline & Lack of client (user) involvement & & $\longrightarrow$ \\
\hline & Excessive involvement of the client & 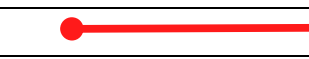 & \\
\hline \multirow{2}{*}{ Vocabulary } & Common vocabulary & $c-$ & \multirow{2}{*}{ 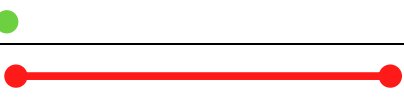 } \\
\hline & Semantic ambiguity & & \\
\hline
\end{tabular}

Hindering factor; based on the case study.

As can be seen in the table, both the factor and its opposite were identified in the project definition stage. Facilitating factors addressed during planning and programming 
stages, were not considered during the conceptual design stage. The following sections elaborate these dynamics in more details.

- Knowledge: sharing of knowledge/lack of sharing knowledge/Loss of acquired knowledge

Sharing of knowledge has been principally identified during planning and programming stages. We have found in the videos and documentation reviewed evidence, such as meeting reports, PowerPoint presentations of all Lean workshops organized, proving that knowledge and information were shared between the design professionals, clinical managers, project managers and users. This result was confirmed by the interviewees. As quoted by a project manager:

"We shared all information about the process with users".

During both stages of planning and programming, five kaizen activities were implemented to facilitate a bidirectional sharing of knowledge between design professionals and users. A member of the clinical management team said:

"It is an approach which, on the one hand, allows professionals to learn new practices and it also allows clinical staff (doctors, nurses, etc.) to know the different limits of the building".

This means that the project team was not the only party that shares information with users, for example regarding constraints of the project, but users also shared information about the general operation of hospitals, patient flow, and different types of clienteles. In this manner, users learn about the reality of architecture and architects learn about the details that are of importance to hospital users. This helps clarify any unclear points about the project that can potentially impede the achievement of client requirements and finally when sharing of knowledge is achieved, sharing of understanding can follow.

Despite its importance, information was not shared as much as in the first two stages in the end of the programming and during the conceptual design stages. Furthermore, the conceptual design stage was not only characterized by discontinuity in knowledge sharing, but also by a loss of previously acquired knowledge. Unlike the first two stages of the project definition, at the beginning of the preliminary design stage different clinicians were not satisfied and did not understand the decisions of architects, as quoted by a clinician:

"At that time, I could not understand why they didn't consider what we have realized during the kaizen 4".

This could be explained by two reasons. Firstly, designers in the conceptual design stage were different from those for the programming stage. Secondly, a non-participative approach was used in the design stage, which means that users were not involved in the process. In other words, switching from a participative to a less participative approach can potentially undo what has been achieved before.

In conclusion, a considerable work was done to facilitate sharing of understanding and knowledge among stakeholders during planning and programming stages when using the Lean-led design approach. However, this knowledge acquired by users during the first two stages was lost: between programming and conceptual design and during the conceptual design stages, since the approach was less participative, and the professionals mandated for this stage were different from those of the other stages. It is noteworthy that sharing of knowledge seems to co-evolve with sharing of understanding, which will be discussed next.

- Understanding: Sharing of Understanding/Lack of Understanding

Sharing of understanding is an important indicator of effective communication. Based on the literature, implementation of the Lean-led design approach should facilitate sharing of understanding since users are involved in the process. However, in our case study, responses in the interviews were sometimes confusing and contradicting. 
Based on perspectives of clinical management team members and the project manager, there was a positive link between implementation of kaizen and level of user understanding:

"Thanks to kaizen, clinicians better understand the development of the project and conceptual choices" [Project Manager].

Different users agree with that, and one of them phrased this as follows:

"These kaizens helped us to understand the architectural decisions made" [patient].

"It helps us understand each other and to see the relationships between the different hospital department" [Clinician].

According to these respondents, when a user is involved in the process, they actively participate and ask questions that increase their understanding and awareness. However, designers in the programming stage responded differently:

"Clinicians believe that architecture only moves the pieces. They do not trust us even if we explain to them that we have other considerations to take into account such as structural and mechanical constraints" [Design Professional].

According to them, users still did not understand the design choices despite the fact they were involved in the process from the beginning. This problem could be due to semantic ambiguity or change in users throughout the project definition stage, since those who participated in the beginning of the process were not necessarily those in the middle or the end of the process.

To sum up, even though Lean-led design was implemented during both the planning and programming stages, it is not possible to assume that a shared understanding necessarily existed between participants during these stages and least of all during the conceptual design stage, where users were less involved. Nevertheless, we have found that this factor remains linked to the need to share knowledge and create a common vocabulary. These three factors that evolve together have been discussed by several researchers (as presented in chapter 3) as the three main pillars of communication.

- Dialogue: group dialogue/lack of dialogue/Division of dialogue groups in silos

This factor was considered during all project definition stages to ensure collective decisions and thus achieve effective communication. However, the involved group members in the dialogue were different in each stage.

In the planning stage, dialogues included members of the Clinical Department, project managers, members of the Ministry of Health, and users of different hospital departments, including patient representatives. All these participants were involved to gather the necessary information to develop the clinical plan.

During the programming stage, group dialogues involved professionals of the programming stage along with the same participants during the planning stage. Here, the objective was to define hospital needs and think about the organization of the premises.

During the first two stages, dialogue groups included a large number of participants (100 to 400 ), frequently gathering together during kaizen activities, while in the preliminary design stage they involved fewer participants.

During the third stage of project definition, dialogue groups did not involve all stakeholders at the same time, and separate smaller groups were created (between 6 and 10). For instance, a dialogue group could involve members of the clinical management team, project managers, and design and construction professionals to discuss project problems or to find solutions. These meetings were usually informal and were held in the project office. Other dialogue groups could involve only the architects with clinicians of a specific hospital department with the objective to discuss the needs of different departments or the proposed design solution. These meetings were also usually informal and occasional.

However, inadequate distribution of participant profiles in dialogue groups was identified by some respondents as an inhibitor to communication and this was identified not only in the preliminary design stage where a non-participative approach was adopted, 
but also during the planning and programming stages even though an inclusive Leanled design was implemented there. One of the objectives of implementing a Lean-led design was to minimize the "silo work" since different stakeholders were involved from the beginning. However, looking back on these activities, according to some members of the clinical management team, the division of discussion groups during planning and programming led to a silo work:

"We grouped together several participants at the same time, during Lean activities to avoid working in silos. However, I think on the contrary, we created silos. We almost missed out on what we wanted to get during the kaizen" [Member of the clinical management].

According to them, although each kaizen involved different stakeholders, the composition of small discussion groups (roundtables) was based on a specific expertise and thus was inadequate. These groups were made up of only the people working in the same department creating a disconnection from other hospital departments that should also be involved.

To conclude, contrary to the dialogue groups developed during the planning and programming stages, dialogue groups were informal and less frequent with fewer participants in the preliminary design stage. This impacted the understanding and satisfaction of different users and created a gap between the first two and the third stage. Furthermore, too many users were involved in the kaizen, but the way they were involved was not the most efficient manner, not only because of their excessive involvement, but also because each discussion group was composed of representants of the same hospital specialty, which led to a "silo" work. This situation does not favor interdisciplinary dialogue and thus mental alignment, which is precisely sought by participatory approaches such the Lean-led design.

- Involvement: Stakeholders (user) early involvement/lack of client involvement

One way to better manage the complexity of a hospital project is to involve users in the project definition process from the beginning. According to the interviewees, early involvement proved to be extremely useful during the process to better understand the needs. For this purpose, the expertise of everyone was mobilized to generate an integrated vision during both planning and programming stages meaning that clinicians and support service staff were brought together to help define the best possible hospital. According to some of the respondents, this project has been a great opportunity and a privilege for them to be able to work together and develop communication and collaboration:

"I really believe in grouping teams, it creates synergies; it creates the setting of common expertise" [Patient].

However, according to one member of the clinical management team, involvement of more than 200 participants at the same time in each kaizen in planning and programming stages can lead to excessive mobilization:

"One of the risks to be avoided is over-mobilization and organizational fatigue around the real estate project" [Member of the clinical management].

Management of this issue and communication among them was not always easy, despite the efforts of organizers to remind participants of the project vision in each step, in order to maintain a harmony between them.

At the end of the programming stage, users were no longer part of the process of conceptual design since the adopted approach at that stage was non-participative. This change in the approach is believed to impact the understanding and engagement of users.

To sum up, involving users and patients and working together with the clinical management team to solve problems is a crucial factor to improve understanding of user needs. It also helps to reduce conflicts between users and improve their communication and engagement. However, it is a double-edged sword since excessive involvement of 
users could hinder communication. Thus, it seems important to involve participants in an efficient and reasonable manner.

- Vocabulary: Common Vocabulary/Semantic Ambiguity

Based on the literature, common vocabulary was one of the most important facilitating factors of communication, which was also identified in our hospital case study. According to the clinical management team, developing a common vocabulary between professionals and clients before and during the kaizen, is necessary for effective communication:

"The secret of our success was the development of a common vocabulary. We encouraged users and architects to use the same vocabulary in order to have a common basis and to better communicate" [Member of clinical management team].

Another respondent agreed with that:

"Without a common vocabulary, we cannot understand each other" [Patient].

In the context of a hospital project, since on the one hand, users are generally not knowledgeable about the technical jargon used by architects, and on the other hand, architects are not familiar with expert medical vocabulary, identifying user needs and properly translating them is a rather difficult task.

However, in spite of the efforts to share a common understanding and vocabulary between different stakeholders from the beginning, a semantic ambiguity between parties seem to continue to exist. In our case study the actors did not use the same vocabulary to refer to the same information or tasks:

"Users often mix process maps (how they will work) versus our architectural plans"

[Design professional of the programming stage].

This hindering factor has been identified during and across different stages, especially when new data and/or actors were present. For instance, while "plan" in architectural field refers to the "design plan," users who participated in kaizen activities used it to refer to both the process mapping and the design plan.

Clinicians and architects use terms in different contexts, obviously medical and spatial, respectively. Therefore, establishing common vocabulary is important for effective communication and common understanding, especially in a dynamic context. However, it is not possible for us reliably conclude that common vocabulary was established during the whole process of project definition of the mega hospital.

\subsubsection{Facilitating Factors}

The Table 3 below contains the only facilitating factor identified in the project definition stage, which is similar to the one found in the literature. As shown in the table, co-locating team members was addressed in all stages. The following section explains this factor in more details.

Table 3. The identified facilitating factor in the case study.

\begin{tabular}{cccc}
\hline Facilitating Factors & Planning Stage & Programming Stage & Conceptual Design Stage \\
\hline Co-locating team members & & \\
\hline & & \\
\hline
\end{tabular}

\section{- Co-Locating Team Members}

The respondents referred to co-locating as one of the biggest advantages of the case study. Actually, more than 220 people including construction professionals, managers, and members of the clinical management team were co-located in an office near the building site since the planning stage.

According to some interviewees, co-locating different identities improved communication and rapid diffusion of information to some extent due to informal meetings: 
"We are more present than the traditional mode. Our clinical management is mixed with the architects and engineers even the project manager is with us. Without this project office, communication would have been more difficult. We're a strong trio" [Member of clinical management team].

In the same line, a construction professional added:

"Being co-located helped us to better communicate and collaborate".

While some interviewees believed that co-locating the stakeholders helps to improve communication among them, others thought that sharing the same workspace does not necessarily lead to better communication. One designer of both the programing and design stages mentioned that:

"Being in a project office does not mean that the quality of communication is better. Of course, everyone is together, but everyone works in their own bubble. We always send emails instead of getting up".

This means that each person works in their own space, even if they are all in the same room or location.

To sum up, the project office can facilitate rapid diffusion of information and interactions between different players, but in this project, it was still challenging to make collaborative conversations since people still tended to communicate in the traditional manner, for example by emails instead of face-to-face interactions although they were co-located. In light of this, it is possible to make some observations regarding the difficulty to change people's habits, especially if there are a lot of participants that do not engage in face-to-face dialogues even if co-located.

\subsubsection{Hindering Factors}

Table 4 contains the hindering factor identified during the preliminary design stage. This factor was newly identified based on the findings of the case study.

Table 4. Hindering factor identified in the case study.

\begin{tabular}{cccc}
\hline Hindering Factors & Planning Stage & Programming Stage & Conceptual Design Stage \\
\hline Dominating actors & & \\
\hline
\end{tabular}

\section{Hindering factor.}

\section{- Dominating Actors}

Dominating actors have more power than others in the process of project definition. Several studies, including Carlile [46], emphasize the close relationship between actor power and transfer of knowledge. This has been identified as a hindering factor for communication in programming and conceptual design stages.

In the chosen case study, architects mandated for the design stage used the power resulting from their knowledge of design to take control of the whole process and did not recognize part of the works previously done by kaizen participants during both the planning and programming stages:

"But every time the architects want to create something new. They don't take into account what we're doing" [Member of the clinical management team].

An example of which is the mock-ups developed by users, clinical managers, and design professionals. The objective of these mock-ups was to define the exact square meters required for each representative hospital room.

However, using their power, architects modified the decisions previously reached by consensus during the kaizen. 
To sum up, in the traditional approach such as the one adopted during the design stage, the architect is the most powerful actor. This dominance can hinder the communication between stakeholders since they do not consider the point of view and the contribution of others. In this approach, the architect is deeply embedded in his practice, knowledge, and tools, and the involvement of other actors in the process of design jeopardizes their position and dominance. Implementing a participative approach during preliminary and design stages with an integrated project delivery method can reduce the architect dominance and balance user and designer voices. In such an approach, the user is part of the process and is thus a member of the design team.

\section{Discussion}

This study addressed the knowledge gap concerning factors that can facilitate or hinder the communication between design professionals and clients during project definition, widely regarded as one of the main challenges that most complex projects strive to successfully achieve.

The findings of this research are several communication factors classified into three main categories: influencing (five), facilitating (one), and hindering (one). As a reminder, we mean by:

- Influencing factors: The ones that can both positively and negatively impact communication, which means that when they are addressed, they facilitate it and when not, they hinder it (ex. vocabulary).

- Facilitating factors: The ones that positively impact communication. When addressed, they facilitate communication and when not addressed they do not hinder it (colocating team members).

- Hindering factors: They negatively impact communication (dominating actors).

These factors were identified by comparing the literature and the case study which not only allowed us to identify the potential similarities and divergences, but also other relevant and novel factors. In fact, all factors identified in the literature were also identified in the case study, while four novel factors were identified based on the case study findings (Table 5).

Table 5. The different factors identified.

Identified in Both Literature and the Case Study

Novel Factors Identified Based on the Case Study

\begin{tabular}{|c|c|c|c|}
\hline Facilitating factor & & ocating team members & \\
\hline \multirow{10}{*}{ Influencing factor } & \multirow{2}{*}{ Knowledge } & Sharing of knowledge & \multirow[t]{2}{*}{ Loss of acquired knowledge } \\
\hline & & Lack of sharing knowledge & \\
\hline & \multirow{2}{*}{ Understanding } & Sharing of understanding & \\
\hline & & Lack of understanding & \\
\hline & \multirow{2}{*}{ Dialogue } & Group dialogue & \multirow{2}{*}{ Division of dialogue groups in silos } \\
\hline & & Lack of dialogue & \\
\hline & \multirow{2}{*}{ Involvement } & Stakeholders (user) early involvement & \multirow[t]{2}{*}{ Excessive involvement of the client } \\
\hline & & Lack of client (user) involvement & \\
\hline & \multirow{2}{*}{ Vocabulary } & Common vocabulary & \\
\hline & & Semantic ambiguity & \\
\hline
\end{tabular}

The factors identified based on the case study were not only identified based on the interviews, but also based on the documentation and videos reviewed. Let us take an example of the "sharing of knowledge" factor. We considered that this factor was addressed 
during the first two stages of project definition because: (1) we have found in the videos and documentation reviewed evidence proving that knowledge and information were shared between the design professionals, clinical managers, project managers and users during the different kaizen; and (2) different respondents expressed that. For instance, a member of the clinical management team quoted that: "The Kaizen not only allowed professionals to better understand medical practices and the reality of clinicians, but also clinical staff (doctors, nurses, etc.) to know the different limits of the building".

Moreover, as can be seen in Table 5, three of four factors newly identified were classified in the influencing category. For instance: loss of acquired knowledge was classified as an influencing factor with two other factors: sharing of knowledge and lack of sharing knowledge. We want to specify here, that it is true that we can present an opposite of every communication factor identified in this study. However, for the sake of intellectual honesty, we decided to only present factors found in the literature or based on the case study. More specifically, if authors or respondents highlighted the factor and its opposite as important to achieve or hinder the communication, we consider both. Otherwise, we only present the factor as facilitating or hindering. This means that it is possible to find a different result in other contexts or case studies.

The number of facilitating and hindering factors that involved each influencing increased based on the case study findings (e.g., based on the literature "Knowledge" was divided into 1 hindering "Lack of sharing knowledge" and 1 facilitating factor "Sharing of knowledge", while based on the case study this factor is divided into 1 facilitating "Sharing of knowledge" and 2 hindering "Lack of sharing knowledge and Loss of acquired knowledge".

Furthermore, some of these new factors were unexpected to be identified even less in a Lean-led design context as a hindering factor, for instance excessive involvement of users or division of dialogue groups in silos. While the majority of authors (such as Grunden and Hagood [16], Schouten and Heusinkveld [18]) have recognized the benefits of involving users to facilitate alignment in the process of project definition, in this study we found that excessive involvement or the division of discussion groups in silos could have an adverse impact.

It is noteworthy that not all the identified factors are addressed during all stages of project definition. While some are only addressed during a specific stage (e.g., dominating actors), others evolve during the project definition process (e.g., sharing of knowledge). Additionally, factors could only be identified at the beginning or the end of a project definition stage (e.g., lack of understanding during the programming stage).

As shown in Figure 3, most facilitating factors (green) which were addressed during the planning and programming stages, were totally ignored or received less attention during the conceptual design stage (e.g., sharing of knowledge, sharing of understanding, group dialogue between users and design professionals). When the facilitating factors disappeared, the hindering ones (red) such as semantic ambiguity or lack of user understanding appeared. According to our analysis, this could be a result of abandoning the participative and adopting the traditional non-participative approach. The facilitating factors were addressed when the participative Lean-led design perspective was implemented. By contrast, the majority of hindering factors were associated with implementation of a traditional (non-participative) project definition approach.

There is a consensus about the importance of Lean methods in the communication between the stakeholders and the success of a project, as phrased by some of them:

"I think all the workshops were really relevant! We wouldn't have arrived without it" [Project manager].

"Thanks to this type of approach, we can better communicate and understand the architects" [Clinician]. 


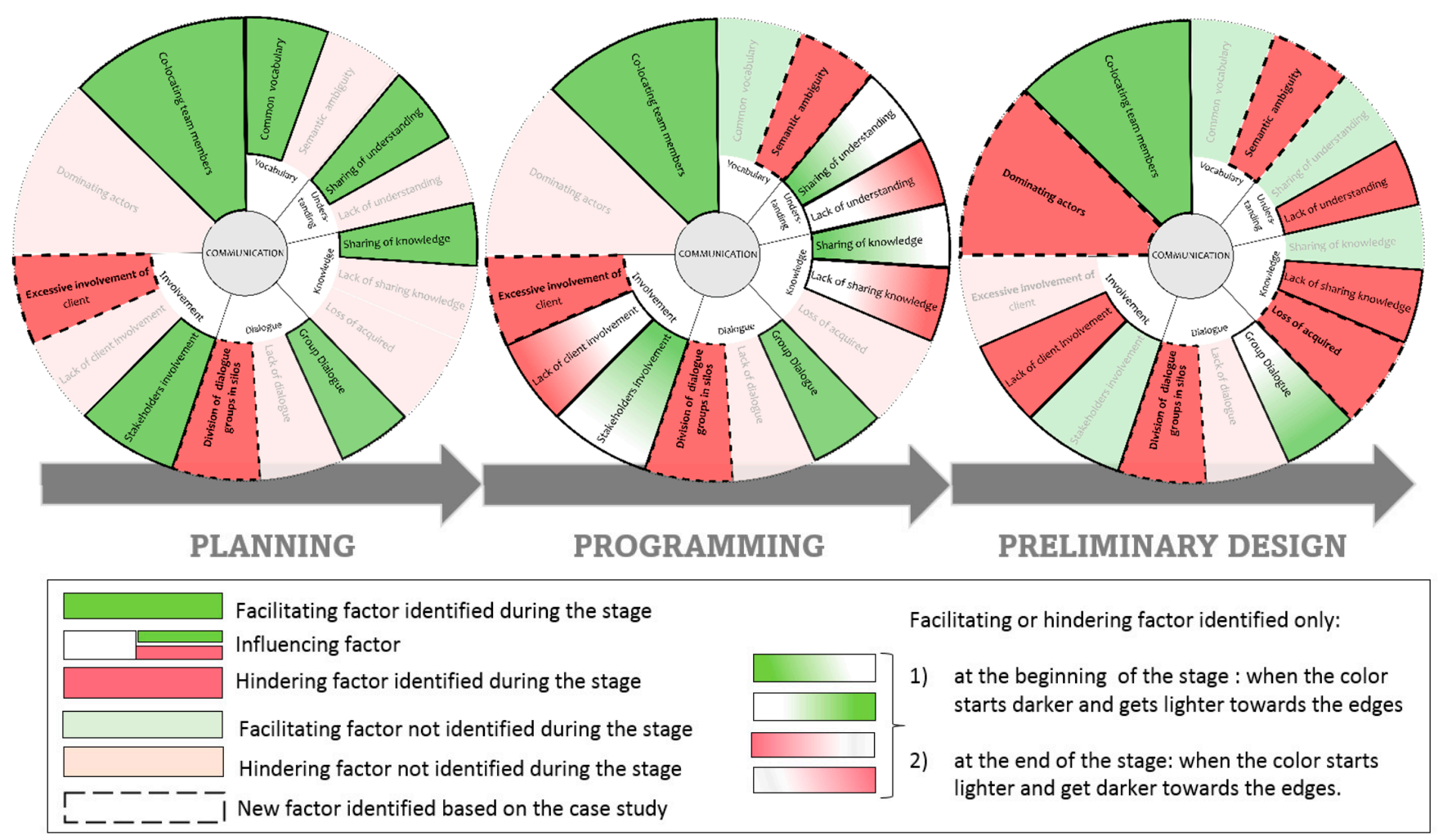

Figure 3. Evolution of factors during project definition stages.

Even though different authors and respondents highlighted the importance of implementing a participative approach such as Lean-led design, we could not demonstrate, based on this research findings, that implementing such a participative approach automatically ensures an effective communication between designers and users.

In addition, it was observed that factors influence each other and evolve together. For instance, sharing of knowledge and common vocabulary positively influenced stakeholder understanding, while a lack of knowledge sharing, and semantic ambiguity negatively affected the understanding. In addition, factors linked to the influencing subcategory were found to be very important in the process of project definition because when a factor that positively influences communication is ignored, a conceptually opposite factor that hinders it comes into effect instead. Despite all the Lean activities to address communication facilitating factors, the majority of factors transformed from facilitating to hindering when the participative approach was abandoned.

Having said that, implementing a participative approach such as Lean-led design seem to promote a continuous communication and thus correspondence between the planning and programming stages while a communication gap between programming and conceptual design stages seem to emerge when a non-participative approach is adopted. It was highlighted by different project managers that having resources and time obviously impacted the implementation of the management approach. According to the project managers, one of the main reasons for the lack of implementing a participative approach during the last stages of the project definition is the lack of resources and time, as quoted by one of them: "We go back to the traditional approach during the design stages because of the budget and time."

\section{Conclusions}

This research study aimed to improve the communication between clients and design professionals during the stage of project definition in a complex context with the assumption that an effective communication provides a better alignment between client needs and design solutions. 
The first contribution of this research is a longitudinal investigation: along the timeline of planning, programming, and schematic design stages, which is usually neglected according to Griffith and Gibson [27]. Our results showed the importance of comprehensive longitudinal assessments and maintenance of communication among the involved parties in a project. Lack of this assessment may lead to loss of previous achievements, comparable to what happened in our mega hospital case study. Another contribution of this research study is introducing a conceptual framework based on theoretical and practical comparisons, finally presenting the communication factors in three categories.

The proposed framework can help managers (e.g., clinical managers or project managers) understand how to attain communication. By analyzing these communication factors, managers can assess, evaluate, and establish corrective strategies to improve the situation at hand. This should also help identify lessons learned for continuous project improvement. The framework can also be used to develop a communication maturity model and be customized to incorporate the contextual parameters of a project. Although the validation of this framework is limited to a single case study, it opens a path of research that has been largely neglected so far. While this qualitative research can hardly accomplish the external validity of a quantitative analysis, it is necessary to recall the originality and uniqueness of such a research context. Furthermore, it is not possible to generalize all the findings, there is still room for generalizing a significant part of it. For instance, although it cannot be assumed that all factors in the conceptual framework will be found in other complex projects, it is safe to believe that some of the factors co-evolve with each other (e.g., common vocabulary and sharing of knowledge). Another point is about the impact of the implementation or not of a participative approach in the existence of some communication factors.

Therefore, the development of this framework is only the first step towards improvement of the project definition process. The findings of this paper are part of a larger empirical investigation aiming to obtain further insight into project definition stages of hospitals for the purposes of maximizing the generation of end user value. Testing the validity of this framework in the context of other projects such as cultural buildings or airports where several functions and different types of users interact, could be considered a direction for further future research.

Author Contributions: Supervision (useful comments and guidance), D.F. and S.B.R.; writingoriginal draft, H.C. All authors have read and agreed to the published version of the manuscript.

Funding: This research was supported by Natural Sciences and Engineering Research Council of Canada.

Institutional Review Board Statement: The study was conducted according to the guidelines of the Declaration of Helsinki, and approved by the Institutional Review Board (or Ethics Committee) of École de technologie supérieure (protocol code H20181105, 15 January 2019).

Informed Consent Statement: Informed consent was obtained from all subjects involved in the study.

Data Availability Statement: Data supporting reported results are available from the corresponding author on reasonable request. The data are not publicly available due to ethical restrictions.

Conflicts of Interest: The authors declare no conflict of interest.

\section{References}

1. Larsen, A.S.A.; Karlsen, A.T.; Andersen, B. Hospital project front-end planning: Current practice and discovered challenges. Proj. Leadersh. Soc. 2020, 1, 100004. [CrossRef]

2. Tzortzopoulos, P.; Codinhoto, R.; Kagioglou, M.; Rooke, J.; Koskela, L. The gaps between healthcare service and building design: A state of the art review. Ambiente Construido 2009, 9, 47-55.

3. Larsen, A.S.A.; Karlsen, A.T.; Andersen, B.; Olsson, N. Exploring collaboration in hospital projects' front-end phase. Int. J. Proj. Manag. 2021, 39, 557-569. [CrossRef]

4. Safapour, E.; Kermanshachi, S. Identifying early indicators of manageable rework causes and selecting mitigating best practices for construction. J. Manag. Eng. 2019, 35, 4018060. [CrossRef] 
5. Forgues, D.; Brunet, M.; Chbaly, H. Lean-led, evidence-based and integrated design: Toward a collaborative briefing process. In Proceedings of the International Conference on Cooperative Design, Visualization and Engineering, Bangkok, Thailand, 24-27 October 2021; pp. 78-85.

6. Pham, A.N. CEO duality and performance of not-for-profit hospitals. Ph.D. Thesis, Walden University, Minneapolis, MN, USA, 2015. Available online: https:/ / www.proquest.com/docview / 1681371426?pq-origsite=gscholar\&fromopenview=true (accessed on 23 August 2021).

7. Whelton, M.; Ballard, G.; Tommelein, I. A knowledge management framework for project definition. J. Inf. Technol. Constr. 2003, 7, 197-212.

8. Winch, G.; Usmani, A.; Edkins, A. Towards total project quality: A gap analysis approach. Constr. Manag. Econ. 1998, 16, 193-207. [CrossRef]

9. Soliman-Junior, J.; Formoso, C.T.; Tzortzopoulos, P. A semantic-based framework for automated rule checking in healthcare construction projects. Can. J. Civ. Eng. 2020, 47, 202-214. [CrossRef]

10. Baldauf, J.P.; Formoso, C.T.; Tzortzopoulos, P.; Miron, L.I.; Soliman-Junior, J. Using Building Information Modelling to Manage Client Requirements in Social Housing Projects. Sustainability 2020, 12, 2804. [CrossRef]

11. Hicks, C.; McGovern, T.; Prior, G.; Smith, I. Applying lean principles to the design of healthcare facilities. Int. J. Prod. Econ. 2015, 170, 677-686. [CrossRef]

12. Apaolaza, U.; Lizarralde, A. Managing Multiple Projects in Uncertain Contexts: A Case Study on the Application of a New Approach Based on the Critical Chain Method. Sustainability 2020, 12, 5999. [CrossRef]

13. Blyth, A.; Worthington, J. Managing the Brief for Better Design; Routledge: London, UK, 2010.

14. Caixeta, M.C.; Fabricio, M.M. Physical-digital model for co-design in healthcare buildings. J. Build. Eng. 2021, 34, 101900. [CrossRef]

15. Caixeta, M.C.B.F.; Tzortzopoulos, P.; Fabricio, M.M. User involvement in building design-A state-of-the-art review. Pós. Rev. Do Programa De Pós-Grad. Em Arquitetura E Urban. Da FAUUSP 2019, 26, e151752. [CrossRef]

16. Grunden, N.; Hagood, C. Lean-Led Hospital Design: Creating the Efficient Hospital of the Future; CRC Press: Boca Raton, FL, USA, 2012.

17. Smith, I.; Hicks, C.; McGovern, T. Adapting Lean methods to facilitate stakeholder engagement and co-design in healthcare. Bmj 2020, 368, m35. [CrossRef] [PubMed]

18. Schouten, H.; Heusinkveld, S.; van der Kam, W.; Benders, J. Implementing lean-led hospital design; lessons gained at a pioneer. J. Health Organ. Manag. 2020, 35, 1-16. [CrossRef]

19. von Danwitz, S. Managing inter-firm projects: A systematic review and directions for future research. Int. J. Proj. Manag. 2018, 36, 525-541. [CrossRef]

20. Yin, R. Case Study Research: Design and Methods (Third Edition); Thousand Oaks: London, UK, 2003; Volume 5.

21. Eisenhardt, K.M. Building theories from case study research. Acad. Manag. Rev. 1989, 14, 532-550. [CrossRef]

22. Myers, M. Qualitative Research in Business \& Management Sage Publications; Sage Publications: London, UK, 2009.

23. Malina, M.A.; Selto, F.H. Communicating and controlling strategy: An empirical study of the effectiveness of the balanced scorecard. J. Manag. Account. Res. 2001, 13, 47-90. [CrossRef]

24. Dima, I.C.; Teodorescu, M.; Gifu, D. New communication approaches vs. traditional communication. Int. Lett. Soc. Humanist. Sci. 2014, 20, 46-55. [CrossRef]

25. Bond-Barnard, T.J.; Fletcher, L.; Steyn, H. Linking trust and collaboration in project teams to project management success. Int. J. Manag. Proj. Bus. 2018, 433. [CrossRef]

26. Construction Industry Institute. Pre-Project Planning Handbook; University of Texas at Austin: Austin, TX, USA, 1995.

27. Griffith, A.; Gibson, J.G. Alignment during preproject planning. J. Manag. Eng. 2001, 17, 69-76. [CrossRef]

28. Bingham, E.; Gibson, G.E., Jr.; El Asmar, M. Identifying Team Selection and Alignment Factors by Delivery Method for Transportation Projects. J. Constr. Eng. Manag. 2019, 145, 04019061. [CrossRef]

29. Alm Lönnefjord, J.; Johansson, R. Global project alignment and performance: Combining Chinese and Western management practices. Available online: https://www.diva-portal.org/smash/get/diva2:1213177/FULLTEXT02 (accessed on 23 August 2021).

30. Whelton, M.; Ballard, G.; Tommelein, I. Application of design rationale systems to project definition-Establishing a research project. In Proceedings of the 9th Conference of the International Group for Lean Construction (IGLC), Singapore, 6-8 August 2020.

31. Kleinsmann, M.; Valkenburg, R. Barriers and enablers for creating shared understanding in co-design projects. Des. Stud. 2008, 29, 369-386. [CrossRef]

32. Ballard, G. Lean project delivery system. White Pap. 2000, 8, 1-6.

33. Huang, J.; Yang, A. Implementing dialogic communication: A survey of IPR, PRSA, and IABC members. Public Relat. Rev. 2015, 41, 376-377. [CrossRef]

34. Rhodes, C. 12'Doing'knowledge at work Dialogue, monologue and power in organisational learning. Res. Knowl. Work Perspect. Case-Stud. Innov. Strateg. 2000, 217, 231-245.

35. Whelton, M.; Pennanen, A.; Ballard, G. Knowledge emergence and adaptive management: An exploration on the co-production of project needs and requirements by client-specialist groups. In Knowledge Management in the Construction Industry: A Socio-Technical Perspective; IGI Global: Hershey, PA, USA, 2005; pp. 251-275.

36. Whelton, M. The Development of Purpose in the Project Definition Phase of Construction Projects; Engineering-Civil \& Environmental Engineering; University of California: Berkeley, CA, USA, 2004; p. 313. 
37. Baiden, B.K.; Price, A.D.; Dainty, A.R. The extent of team integration within construction projects. Int. J. Proj. Manag. 2006, 24, 13-23. [CrossRef]

38. Johnson, K.M.; Mazur, L.; Chadwick, J.; Pooya, P.; Amos, A.; McCreery, J. Integrating lean exploration loops into healthcare facility design: Schematic phase. HERD: Health Environ. Res. Des. J. 2017, 10, 131-141. [CrossRef]

39. Whelton, M.; Ballard, G. Wicked problems in project definition. In Proceedings of the International Group for Lean Construction 10th Annual Conference, Gramado, Brazil, 6-8 August 2002.

40. Mazur, L.M.; Johnson, K.; Pooya, P.; Chadwick, J.; McCreery, J. Integrating lean exploration loops into healthcare facility design: Programming phase. HERD Health Environ. Res. Des. J. 2017, 10, 116-130. [CrossRef]

41. Chocron, P.D.; Schorlemmer, M. Vocabulary alignment in openly specified interactions. J. Artif. Intell. Res. 2020, 68, 69-107. [CrossRef]

42. Heineman, G.; Zeiss, A. Team Performance in Health Care: Assessment and Development; Springer Science \& Business Media: Berlin, Germany, 2002.

43. Van den Bulte, C.; Moenaert, R.K. The effects of R\&D team co-location on communication patterns among R\&D, marketing, and manufacturing. Manag. Sci. 1998, 44, S1-S18.

44. Dietrich, P.; Dalcher, D.; Eskerod, P.; Sandhawalia, B. The Role of Project Collaboration Quality and Knowledge Integration Capability in Multi-Partner Projects; Project Management Institute: Washington, DC, USA, 2010.

45. Forgues, D.; Lejeune, A. Value generation through integrated teams: A socio-cognitive approach. J. Civ. Eng. Archit. 2011, 5, 13-21.

46. Carlile, P.R. A pragmatic view of knowledge and boundaries: Boundary objects in new product development. Organ. Sci. 2002, 13, 442-455. [CrossRef] 